\title{
Self- And Peer-Assessments of Team-EfFectiveness in a First Year Engineering Design CoUrSe
}

\author{
Patricia Kristine Sheridan, Doug Reeve, and Greg Evans \\ Institute for Leadership Education in Engineering, University of Toronto \\ patricia.sheridan@utoronto.ca,doug.reeve@utoronto.ca,greg.evans@utoronto.ca
}

\section{INTRODUCTION}

Many first-year design courses in engineering take place in large classes (100-1000 students), where a significant portion of the student's course grade is attributed to a team project. In these large classes most students receive limited, or no, personalized assessment or feedback to guide their ongoing learning of effectiveness in teams due to resource constraints (e.g. limited interaction time with instructors or teaching assistants). As a result, students are not provided a foundation upon which to continuously improve their effectiveness as they participate in different teams throughout their degree.

A web-based tool is being designed to create a safe, virtual environment in which students can learn about their team-effectiveness competencies through the use of self- and peer-assessment in their project teams [1]. Specifically, this intervention provides students with a team-effectiveness framework to create a common language by which structured feedback can be provided based on observable behaviours and competencies.

A pilot study to assess the utility of this framework in facilitating useful feedback was tested in the Winter 2012 term of a 250 student cornerstone design course, Praxis II, in first year Engineering Science. The objective of the study was to assess whether students can be guided to provide useful feedback on team-effectiveness to their teammates using our team-effectiveness framework.

\section{METHODOLOGY}

Before providing assessments, the class attended three half-hour lectures on team-effectiveness behaviours, and how these behaviours manifest in highly-effective, high performance teams. Following this, in week 7 of a 15 week term, students were asked to provide self- and peerassessments on their effectiveness as team members.

The class was randomly divided 52/48 into a control and an experiment group. The control group was requested to provide free-form feedback to the prompt: "Please provide feedback to yourself and your team members based on your/their team effectiveness over the course of this project". The experiment group was asked to assess their and their team member's behaviours using our framework of team-effectiveness [1]. Each of the 27 observable competencies used a descriptive Likert scale as an assessment rubric to normalize variation in student understanding of the behaviours and responses.

One week after completing the feedback, students received their self- and peer- assessments as feedback for review. At the end of the course, students in both groups completed the same survey on the usefulness of the feedback they received. Questions in the survey analysed the quantity, depth and breadth of the feedback as well as its motivation to incite students to improve their teameffectiveness.

\section{PRELIMINARY FINDINGS}

Preliminary findings from the survey indicated that both the experiment and control groups found the feedback to be useful. Both indicated that, on average, they received feedback structured in an understandable and positively phrased manner. Students in the experiment group perceived that they overall received feedback on a broader range of topics than the control group, in particular on their organizational and relational behaviours, their ability to resolve conflict, and their ability to appreciate differences. This finding is expected as we prescribed a set list of behaviours to assess. Students in the experiment group were, on average, more motivated to improve their performance based on the feedback than were students in the control group.

Preliminary findings indicate the framework to be successful in guiding useful team-effectiveness feedback. Further analysis will provide more information on the utility of the framework.

\section{Acknowledgements}

This work was supported by the Higher Education Quality Council of Ontario, the Dorothy and William Palm Queen Elizabeth II Graduate Scholarship in Science and Technology, and the University of Toronto Open Fellowship Fund.

\section{References}

[1] P.K. Sheridan, G. Evans, and D. Reeve, "A Proposed Framework for Teaching Team-effectiveness in Team-based Projects," American Society for Engineering Education Conference, San Antonio, TX, 2012. 